\title{
PEMBERDAYAAN SISWA SEBAGAI KADER KESEHATAN DALAM PROGRAM EDUKASI KESEHATAN REPRODUKSI REMAJA DI SMP SWASTA MEDAN
}

\author{
Empowerment of Students as a Health Cadre in Youth Production of Health \\ Education Private Vocational School in Medan
}

\author{
Nur Asnah Sitohang ${ }^{1}$, Diah Lestari Nasution², Cut Adeya Adella ${ }^{3}$ \\ ${ }^{1,2}$ Dosen Fakultas Keperawatan Universitas Sumatera Utara, Medan \\ ${ }^{3}$ Dosen Fakultas Kedokteran Universitas Sumatera Utara, Medan \\ Email : nur75asnah@yahoo.co.id
}

\begin{abstract}
Abstrak
Kesehatan reproduksi dan seksualitas remaja di Indonesia masih rendah, ini terlihat dari banyaknya kasus kehamilan di luar nikah, kekerasan masa pacaran dan aborsi dengan obat-obatan yang beresiko tinggi. Pemahaman remaja akan kesehatan reproduksi menjadi bekal remaja dalam berperilaku sehat dan bertanggung jawab. Tetapi tidak semua remaja memperoleh informasi yang cukup dan benar tentang kesehatan reproduksi. Keterbatasan pengetahuan dan pemahaman ini dapat membawa remaja ke arah perilaku berisiko. Hal ini disebabkan karena kurangnya informasi mengenai seksualitas dan reproduksi. Kader kesehatan mempunyai peran besar dalam upaya mewujudkan derajat kesehatan masyarakat yang optimal.Pengabdian masyarakat ini dilaksanakan di dua (2) SMP yaitu SMP Swasta Dharma Pancasila (260 siswa dan kader yang dilatih 21 kader) dan SMP Swasta Al-Fhatiyan Medan (199 siswa dan kader yang dilatih 16 siswa). Metode yang digunakan adalah dengan : 1. penyuluhan dengan materi kesehatan reproduksi remaja; 2.pelatihan kader;3. pendampingan kader.4. evaluasi keberhasilan program:pre test dan post test kader dan siswa peserta penyuluhan. Berdasarkan hasil kuesioner yang dibagikan kepada siswa diperoleh data mayoritas usia 13 tahun(47.5\%), jenis kelamin laki -laki (54\%),pendidikan orang tua SMA (62\%) dan pekerjaan wiraswata (96.6\%). Hasil uji $t$ dependen diperoleh data, rata - rata pengetahuan sebelum penyuluhan kesehatan 26.23 dan setelah penyuluhan kesehatan39.58. Beda mean 13.349 dan standar deviasi 3.911 dan 95\% CI 13.707 - 12.990. Berdasarkan hasil uji statistic diperoleh nilai $\mathrm{P}=0.001$ maka dapat disimpulkan ada pengaruh kader kesehatan reproduksi remaja terhadap pengetahuan siswa. Untuk sikap diperoleh data rata - rata sikap sebelum penyuluhan 27.57 dan setelah penyuluhan 39.58. Beda mean 13.349 dan standar deviasi 3.802 dan 95\% CI 12.362 - 11.664. Berdasarkan hasil uji statistik diperoleh nilai $\mathrm{P}=0.001$ maka dapat disimpulkan ada pengaruh kader kesehatan reproduksi remaja terhadap sikap siswa. Kegiatan PkM ini bermanfaat dalam meningkatkan pengetahuan dan sikap remaja terhadap kesehatan reproduksi remaja. Dengan bertambahnya pengetahuan maka akan mempengaruhi sikap remaja terhadap perilaku seksual berisiko, dan bila sikap remaja terhadap perilaku seksual baik maka diharapkan remaja juga berperilaku seksual yang baik pula dan remaja diharapkan lebih bertanggung jawab terhadap kesehatan reproduksinya
\end{abstract}

Kata Kunci: kader, edukasi, kesehatan, reproduksi, remaja

\begin{abstract}
Adolescent reproductive and sexuality health in Indonesia is still low, this can be seen from the many cases of pregnancy out of wedlock, violence during courtship and abortion with high-risk drugs. The understanding of adolescents about reproductive health is the provision of adolescents in healthy and responsible behavior. But not all teenagers get information about reproductive health. This limitation of knowledge and understanding can bring teenagers towards risky behavior. This is a lack of information about sexuality and reproduction. Cadres health has a big role in realizing the optimal level of community health. Community service is carried out in two (2) junior high schools, namely Dharma Pancasila Private Junior High School (260 students and 21 cadres trained) and Al-Fhatiyan Private Middle School Medan (199 students and cadres trained by 16 students). The method used is by: 1. counseling with material on adolescent reproductive health; 2. cadre training; 3. Cadre mentoring. Evaluation of program success: pre test and post test cadres and student participants. Based on the results of the questionnaires distributed to students, the majority of data was 13 years old (47.5\%), male sex (54\%), high school parents education $(62 \%)$ and entrepreneurial work $(96.6 \%)$. The results of the dependent test obtained data, average
\end{abstract}


knowledge before health education 26.23 and after health education39.58. The mean difference is 13,349 and the standard deviation is 3,911 and 95\% CI 13,707-12,990. Based on the results of statistical tests obtained $\mathrm{P}=0.001$, it can be concluded that there is an influence of adolescent reproductive health cadres on student knowledge. For attitudes obtained data on average attitudes before counseling 27.57 and after counseling 39.58. The mean difference is 13,349 and the standard deviation is 3,802 and 95\% CI 12,362 11,664 . $\mathrm{P}$ value $=0.001$ it can be concluded that there is an influence of adolescent reproductive health cadres on student attitudes. This PKM activity is useful in increasing knowledge and attitudes towards adolescent reproductive health. With increased knowledge of the behavior of adolescents to risky sexual behavior, and if the attitudes of adolescents towards sexual behavior are good, it is expected that sexually well and adolescents are expected to be responsible for their reproductive health

Keywords: cadres, education, health, reproduction, adolescents

\section{PENDAHULUAN}

Kesehatan reproduksi dan seksualitas remaja di Indonesia masih rendah, ini terlihat dari banyaknya kasus kehamilan diluar nikah, kekerasan masa pacaran dan aborsi dengan obat-obatan yang beresiko tinggi. Data konseling selama 2004 menunjukkan bahwa kehamilan tidak dikehendaki menunjukkan 560 kasus reproduksi dengan proporsi usia dibawah 18 tahun mencapai $10,89 \%$. Sebagian remaja tersebut berusia 14 hingga 24 tahun dan pengetahuan mereka tentang resiko melakukan hubungan seks masih rendah. Hal ini disebabkan karena kurangnya informasi mengenai seksualitas dan reproduksi (Yanti. 2011)

Pemerintah telah menjalankan program PIK-KRR yang bertujuan meningkatkan perilaku kesehatan remaja menjadi lebih baik. Tetapi hasilnya tidak sesuai dengan realitas perilaku seksual dan resiko seksual yang dihadapi remaja karena :(1)pendidikan seksualitas dan kesehatan reproduksi yang sudah diberikan pada jenjang SMP lebih menitikberatkan pada aspek biologis semata; (2) masih adanya anggapan bahwa seksualitas merupakan hal yang tabu untuk diberikan di sekolah;(3) pendidikan cenderung menekankan pada bahaya dan resiko seks pranikah dari sudut pandang moral dan agama. (4) pendidikan belum memandang aspek pentingya relasi gender dan hak remaja dalam kesehatan reproduksi dan seksual remaja. (Pakasi \&Kartikawati.2013)

Pemahaman remaja akan kesehatan reproduksi menjadi bekal remaja dalam berperilaku sehat dan bertanggung jawab. Tetapi tidak semua remaja memperoleh informasi yang cukup dan benar tentang kesehatan reproduksi. Keterbatasan pengetahuan dan pemahaman ini dapat membawa remaja ke arah perilaku berisiko.

Oleh sebab itu perlu dilakukan diberi pengertian, bimbingan dan dukungan dari lingkungan disekitarnya agar dalam sistem perubahan tersebut terjadi pertumbuhan dan perkembangan yang sehat sedemikian rupa sehingga kelak remaja menjadi manusia dewasa yang sehat secara jasmani, rohani dan sosial (Kumalasari \& Andyantoro, 2012).

Kader kesehatan mempunyai peran besar dalam upaya mewujudkan derajat kesehatan masyarakat yang optimal (Yulifah \& Yuswanto, 2012, hlm.146). Pembinaan kader kesehatan reproduksi remaja dilakukan untuk memberikan informasi dan pengetahuan yang berhubungan dengan perilaku hidup sehat bagi remaja, di samping juga untuk mengatasi masalah yang ada (Kumalasari \& Andhyantoro, 2012)

Penelitian Sitohang Nasution \& Adela (2016) yang bertujuan untuk mengetahui bagaimana pengaruh kader kesehatan reproduksi remaja terhadap pengetahuan remaja. Desain penelitian ini adalah quasy eksperimen. Penelitian ini menggunakan dua kelompok responden, kelompok intervensi di SMP 28 dan kontrol di SMP Negeri 9 Medan. Analisis data menggunakan uji $t$ dependen dan independen. Sampel dalam penelitian ini berjumlah 990 siswa. Teknik samplingnya adalah purposive sampling. Berdasarkan hasil penelitian pada kelompok intervensi ditemukan mayoritas $47,5 \%$ berusia 13 tahun, jenis kelamin laki-laki 54\%, pendidikan orang tua SMA $62 \%$ dan $96,6 \%$, pekerjaan wiraswata. Pada kelompok kontrol, mayoritas responden berusia 14 
tahun dan 37,3\%, 58,8\% jenis kelamin perempuan, pendidikan sekolah menengah $58,2 \%$ dan $76,5 \%$ wiraswasta. Berdasarkan hasil uji statistik ( $t$ dependen) diperoleh nilai $\mathrm{P}=0,001$, maka dapat disimpulkan bahwa ada pengaruh kader kesehatan reproduksi remaja terhadap pengetahuan responden. Berdasarkan hasil uji statistik ( $t$ independen) diperoleh nilai $\mathrm{P}=0,001$ maka dapat disimpulkan ada perbedaan pengetahuan responden di SMPN 28 dan SMPN 9 Medan.

\subsection{Permasalahan Mitra}

- Perilaku berpacaran dikalangan siswasiswi yang sudah mengkhawatirkan terutama dengan kemajuan tehnologi (handphone)

- Meningkatnya kasus kehamilan pra nikah dan kehamilan tidak diinginkan (KTD)pada remaja di Kota Medan

- Belum pernah ada PIK-KRR (Pusat Informasi dan Konseling Kesehatan Reproduksi Remaja) pada kedua mitra.

\section{TARGET DAN LUARAN}

Kader merupakan orang terdekat yang berada ditengah-tengah masyarakat, yang diharapkan dapat memegang pekerjaan penting khusus setiap permasalan yang berkaitan dengan kesehatan. Sedangkan menurut WHO (1995), kader kesehatan masyarakat adalah laki-laki atau wanita yang dipilih oleh masyarakat dan dilatih untuk menangani masalah-masalah kesehatan perorangan maupun masyarakat serta untuk bekerja dalam hubungan yang amat dekat dengan tempat-tempat pemberian pelayanan kesehatan (Yulifah \& Yuswanto. 2012)

Kader kesehatan mempunyai peran besar dalam upaya meningkatkan kemampuan masyarakat menolong dirinya untuk mencapai derajat kesehatan yang optimal.Pelatihan kader merupakan salah satu kegiatan unuk mempersiapkan kader agar mampu berperan serta dalam upaya mewujudkan derajat kesehatan masyarakat yang optimal.Dalam melakukan pelatihan kader, pengetahuan dan keterampilan yang dilatihkan harus disesuaikan dengan tugas kader dalam mengambangkan program kesehatan.Pelatihan kader dimaksudkan untuk meningkatkan pengetahuan, kemauan, dan kemampuan kader dalam pelaksanaan kegiatan yang berkaitan dengan kesehatan (Yulifah \& Yuswanto. 2012).

Pembinaan kesehatan reproduksi remaja bertujuan untuk memberikan informasi dan pengetahuan yang berhubungan dengan dengan perilaku hidup sehat bagi remaja. Disamping mengatasi masalah yang ada,pengetahuan yang memadai dan adanya motivasi untuk menjalani masa remaja secara sehat, diharapkan para remaja mampu memelihara kesehatan dirinya agar dapat memasuki masa kehidupan berkeluarga dengan reproduksi sehat (Widyastuti, et al. 2009).

Target luaran kegiatan program pengabdian masyarakat ini adalah dihasilkannya: meningkatnya pengetahuan,sikap dan tindakan remaja tentang kesehatan reproduksi,adanya kader kesehatan reproduksi remaja di SMP Swasta Dharma Pancasila dan SMP Swasta AlFhatiyan serta diharapkan kedua SMP ini menjadi model percontohan untuk sekolah lain di kota Medan dan sekitarnya,adanya modul kesehatan reproduksi remaja.

\section{METODE PELAKSANAAN}

Berdasarkan permasalahan yang telah dikemukakan, maka dalam kegiatan ini metode yang digunakan adalah dengan :

1. Memilih kader yaitu siswa yang berprestasi ( rangking 1-3 dari setiap kelas tiga ). Adapun tujuan memilih siswa berprestasi adalah agar memudahkan dalam menguasai materi dan memberi penyuluhan.

2. Pre test kader tujuannya untuk mengetahui pengetahuan dan sikap remaja tentang kesehatan reproduksi

3. Pelatihan kader remaja selama dua (2): minggu dengan materi tehnik komunikasi dan konseling,tumbuh kembang remaja, kebersihan organorgan genital (personal hygien), hubungan seksual pranikah, penyakit menular seksual (PMS) HIV/AIDS.

4. Post test kader untuk mengetahui pemahaman kader terhadp materi kesehatan reproduksi dan kemampuan konseling. Waktu yang diberikan untuk 
menjawab kuesioner pada saat tes awal (pretest) dan tes akhir (posttest) adalah masing - masing 60 menit

5. Pendampingan kader : setelah kader remaja menguasai materi, kemudian kader remaja memberikan penyuluhan kepada teman-temannya (peer group) Setiap kelompok terdiri dari 10 siswa. Media yang digunakan leaflet.

6. Kepada seluruh siswa siswi yang mengikuti penyuluhan oleh kader akan dilakukan pre test dan post test sebagai evaluasi terhadap pengetahuannya tentang kesehatan reproduksi.

\section{HASIL DAN LUARAN YANG DICAPAI}

Kegiatan diawali dengan pre test kepada kader dan siswa pada kedua SMP. Kemudian kader dilatih terkait materi kesehatan reproduksi. Kemudian kader didampingi melakukan penyuluhan kepada teman sebayanya. Setelah dilakukan penyuluhan dilakukan post test. Hasilnya adalah sebagai berikut:

4.1. Karakteristik responden

Tabel 1. Karakteristik responden kelompk intervensi dan kelompok kontrol di SMP Dharma Pancasila dan SMP Alfitiyan

Medan tahun 2018

\begin{tabular}{lcc}
\hline Variabel & f & \% \\
\hline Usia & & \\
$-\quad 11$ tahun & 3 & 0.7 \\
$-\quad 12$ tahun & 122 & 26.5 \\
$-\quad 13$ tahun & 219 & 47.5 \\
$-\quad 14$ tahun & 110 & 23.9 \\
$-\quad 15$ tahun & 5 & 1.1 \\
$-\quad 16$ tahun & 0 & 0 \\
\hline Jenis kelamin & & \\
$-\quad$ Perempuan & 209 & 46 \\
$-\quad$ Laki-laki & 250 & 54 \\
\hline Pendidikan & & \\
orang tua & 14 & 3 \\
$-\quad$ SD & 47 & 10 \\
$-\quad$ SMP & 282 & 62 \\
$-\quad$ SMA & 115 & 25 \\
$-\quad$ PT & & \\
\hline Pekerjaan & \\
$\quad$ PNS & 62 & 13.4 \\
\hline
\end{tabular}

\begin{tabular}{llll}
\hline- & Wiraswasta & 397 & 96.6 \\
\hline
\end{tabular}

Berdasarkan tabel 1 ditemukan data mayoritas usia 13 tahun(47.5\%),jenis kelamin laki -laki (54\%),pendidikan orang tua SMA (62\%) dan pekerjaan wiraswata $(96.6 \%)$.

\subsection{Pengetahan Siswa}

Tabel 2. Pengetahuan siswa sebelum dan sesudah dilakukan penyuluhan kesehatan di SMP Dharma Pancasila dan SMP Alfitiyan Medan tahun 2018

\begin{tabular}{lcccc}
\hline Variabel & Mean & $\begin{array}{c}\text { Stan } \\
\text { dar } \\
\text { devia } \\
\text { si }\end{array}$ & $\begin{array}{c}\text { Minim } \\
\text { um- } \\
\text { maksi } \\
\text { mum }\end{array}$ & $\begin{array}{c}\text { 95\% } \\
\text { CI }\end{array}$ \\
\hline $\begin{array}{l}\text { Pengeta- } \\
\text { huan }\end{array}$ & & & & \\
Pre test & 26.23 & 4.01 & $4-30$ & - \\
& & & & 26.60 \\
& & & & 39.51 \\
- post test & 39.58 & 0.744 & $30-40$ & - \\
& & & & 39.65 \\
& & & & \\
\hline
\end{tabular}

Berdasarkan tabel 2 diperoleh hasil sebelum intervensi,rata-rata skor pengetahuan 26.23, standar deviasi 4.01,nilai minimum 4 dan maksimum 30,95\%CI 25.88-26.60. Setelah dilakukan penyuluhan kesehatan rata-rata 39.58,standar deviasi 0.744 ,nilai minimum 30 dan nilai maksimum $40,95 \%$ CI 39.51 39.65

4.3. Sikap siswa sebelum dan setelah diberi penyuluhan kesehatan

Tabel 3. Sikap siswa sebelum dan sesudah dilakukan penyuluhan kesehatan di SMP Dharma Pancasila dan SMP Alfitiyan Medan tahun 2018 


\begin{tabular}{lccc}
\hline Variabel & Mean & $\begin{array}{c}\text { Standar } \\
\text { deviasi }\end{array}$ & $95 \%$ CI \\
\hline Sikap: & & & $27.23 .-$ \\
- pretest & 27.57 & 3.647 & 27.90 \\
- post test & 39.58 & 0.744 & $39.51-$ \\
& & & 39.65 \\
\hline
\end{tabular}

Berdasarkan tabel 3 diperoleh data rata -rata skor sikap sebelum 27.57,standar deviasi 3.647,nilai minimum 12 dan maksimum 36,95\%CI 27.23-27.90. Setelah dilakukan penyuluhan kesehatan rata - rata 39.58 ,standar deviasi 0.744 ,nilai minimum 30 dan nilai maksimum $40,95 \%$ CI 39.51 39.65

\subsection{Pengaruh kader kesehatan reproduksi} remaja terhadap pengetahuan siswa di SMP Dharma Pancasila dan SMP Alfitiyan Medan

\section{Tabel 4}

Pengaruh kader kesehatan reproduksi remaja terhadap pengetahuan siswa di SMP Dharma Pancasila dan SMP Alfitiyan Medan 2018

\begin{tabular}{|c|c|c|c|c|c|}
\hline Variabel & $\begin{array}{l}\text { Me } \\
\text { an }\end{array}$ & $\begin{array}{c}\text { Bed } \\
\text { a } \\
\text { mea } \\
\text { n }\end{array}$ & SD & $\begin{array}{c}95 \% \\
\text { CI }\end{array}$ & $\begin{array}{c}P \\
\text { val } \\
\text { ue }\end{array}$ \\
\hline \multicolumn{6}{|l|}{ Pengeta } \\
\hline huan & 26. & 13.3 & 3.9 & 13.7 & 0.0 \\
\hline Pre test & 23 & 49 & 11 & 07- & 01 \\
\hline \multirow[t]{2}{*}{ Post test } & 39. & & & 12.9 & \\
\hline & 58 & & & 90 & \\
\hline
\end{tabular}

Berdasarkan tabel 4 diperoleh rata rata pengetahuan sebelum intervensi 26.23 dan setelah tindakan 39.58. Beda mean 13.349 dan standar deviasi 3.911 dan $95 \%$ CI 13.707 - 12.990. Berdasarkan hasil uji statistik diperoleh nilai $\mathrm{P}=0.001$ maka dapat disimpulkan ada pengaruh kader kesehatan reproduksi remaja terhadap pengetahuan siswa.

4.5. Pengaruh kader kesehatan reproduksi remaja terhadap sikap siswa di SMP Dharma Pancasila dan SMP Alfitiyan Medan
Tabel 5. Pengaruh kader kesehatan reproduksi remaja terhadap sikap siswa di SMP Dharma Pancasila dan SMP Alfitiyan Medan tahun 2018

\begin{tabular}{cccccc}
\hline $\begin{array}{c}\text { Vari } \\
- \\
\text { abel }\end{array}$ & $\begin{array}{c}\text { Mea } \\
\mathrm{n}\end{array}$ & $\begin{array}{c}\text { Beda } \\
\text { mean }\end{array}$ & $\begin{array}{c}\text { SD } \\
\text { CI } \\
\text { Sikap }\end{array}$ & $\begin{array}{c}27.5 \\
\text { Pre }\end{array}$ & $\begin{array}{c}12.01 \\
\text { valu } \\
\text { e }\end{array}$ \\
test & 39.5 & 3 & 2 & $2-$ & 1 \\
Post & 8 & & & 11.66 & \\
test & & & & 4 & \\
\hline
\end{tabular}

Berdasarkan tabel 5 diperoleh data rata - rata sikap sebelum intervensi 27.57 dan setelah tindakan 39.58. Beda mean 13.349 dan standar deviasi 3.802 dan $95 \%$ CI 12.362 - 11.664. Berdasarkan hasil uji statistik diperoleh nilai $\mathrm{P}=0.001$ maka dapat disimpulkan ada pengaruh kader kesehatan reproduksi remaja terhadap sikap siswa di SMP Pancasila dan SMP Alfitiyan Medan.

\section{KESIMPULAN DAN SARAN}

Kegiatan PkM ini bermanfaat dalam meningkatkan pengetahuan dan sikap remaja terhadap kesehatan reproduksi remaja. Pendidikan kesehatan yang dilakukan dengan metode ceramah, diskusi, tanya jawab dan studi kasus dengan menggunakan alat bantu LCD proyektor dengan menyajikan banyak gambar ternyata efektif untuk merubah pengetahuan remaja tentang kesehatan reproduksi. Dengan bertambahnya pengetahuan maka akan mempengaruhi sikap remaja terhadap perilaku seksual berisiko, dan bila sikap remaja terhadap perilaku seksual baik maka diharapkan remaja juga berperilaku seksual yang baik pula dan remaja diharapkan lebih bertanggung jawab terhadap kesehatan reproduksinya. 
DAFTAR PUSTAKA

Aryani, N. 2010. Efektifitas Program PIKKRR Terhadap Peningkatan Pengetahuan Kespro Remaja di SMU Al-Wasliyah Medan Tahun 2010 dari website Http://www.Repository.USU.ac.id/B itstrem/12345678/.../Cover.pd... (tanggal 12 Desember 2014 jam 11.30 WIB).

Benita, N, R. 2012. Pengaruh Penyuluhan TerhadapTingkat Pengetahuan Kesehatan

Http:www.eprints.undip.ac.id/.../Nydia_Ren a_Benita... (tanggal 12 Desember 2014 jam 11.40 WIB)

Buzarudia.F., Fitriangga.A., Putri. E. A.(2013). Efektivitas penyuluhan kesehatan remaja terhadap tingkat pengetahuan siswa SMAN 6 Kec.Pontianak Timur. (Skripsi mahasiswa)

Kumalasari, I., \& Andhyantoro. (2012). Kesehatan Reproduksi untuk Mahasiswa Kebidanan dan Keperawatan. Jakarta : Salemba Medika.

Madani, Yusuf. (2003). Pendidikan seks untuk anak dalam Islam : panduan bagi orang tua, ulama, guru dan kalangan lainnya. Jakarta: Pustaka Zahra.

Sitohang.N.,Nasution.D.L.,Adela.C.A.

(2016). Model edukasi kesehatan remaja di SMP Negeri Medan (dipublikasikan pada International Nursing Science Confrence UI Jakart)
Pakasi.D.T.,Kartikawati.R.(2013).Antara Kebutuhan dan tabu:pendidikan seksualitas dan kesehatan reproduksi bagi remaja SMA. Makara Seri Kesehatan.2013.17(2):79-87

Paramita.,Widjianti., Suparnoto. (2006). Pelaksanaan PIK-KRR di Puskesmas kota Madiun dan Kabupaten Tulungagung. Buletin penelitian sistem kesehatan. Vol.9.no.3.Juli 2006:156-163

Paramastri, Prawitasari, Prabandari \& Ekowarni, Booklet sebagai Media Pencegahan Terhadap Kekerasan Seksual Pada Anak, Artikel Penelitian diakses tanggal 14-102015

Yulifah, R., Yuswanto, T.J.A. (2012). Asuhan Kebidanan Komunitas. Jakarta : Salemba Medika.

Widyastuti, Y., Rahmawati, A,. \& Purnamaningrum, Y.E. (2009). Kesehatan Reproduksi. Yogyakarta : Penerbit Fitramaya.

Wulandari.V.F.,Nirwana.H.,Nurfarhanah.(2 012). Pemahaman siswa mengenai kesehatan reproduksi remaja melalui layanan informasi. Jurnal ilmiah konseling.Vol.1.no.1. Januari 2012. Hal. 1-9. 